\title{
Impact of Vibrations on the Final Characteristics of Normal and Self-compacting Concrete
}

\author{
Sandra Juradin*, Goran Baloević, Alen Harapin \\ Faculty of Civil Engineering, Architecture and Geodesy, University of Split, \\ Matice hrvatske 15, Split, Croatia
}

Received: February 13, 2013; Revised: November 10, 2013

\begin{abstract}
The quality and durability of normal concrete directly depends on the number and the shape of voids, so, in order to produce durable concrete, it is necessary to reduce the amount of air that is trapped inside the concrete, which is usually done by vibrating the concrete in the mixing stage or the casting stage. Self-compacting concretes are concretes that, in principle, don't require vibrating during casting. Such concretes possess enough compactness and flowability through gravity that during pouring they fill all the space in the formwork. However, it is frequently the case that the ideal self-compacting concrete that is produced in a laboratory cannot be produced on a construction site so such concretes require additional vibrations. The work examines the impact that the introduction of vibrations during mixing and during casting has on the final appearance and the compressive strength of normal and self-compacting concretes. Achieved results confirm that vibrating during the mixing stage can improve the workability of fresh concrete but not its final strength, especially for self-compacting concretes, while vibrating in the casting stage significantly contributes to the final strength of the concrete.
\end{abstract}

Keywords: self-compacting concrete, impact of vibrations during the mixing stage, impact of vibrations during the casting stage, experimental testing, concrete compressive strength

\section{Introduction}

Concrete is the result of the desire to produce a strong and cheap building material that would enable fast and inexpensive construction with acceptable durability of the structure. The first goal has essentially been achieved, while, on the question of durability, concrete is still lagging after its role-model: the stone. That is why in modern codes, durability is accepted as a parameter of quality as important as the parameters for the stability of the structure.

In the beginning concrete was used mainly for larger structures that contained little or no reinforcement. Unlike the modern concept of fresh concrete as a plastic mass that can easily be cast, the early concrete mixes had a small amount of water and were cast in small layers that were hand compacted. Appearance of water on the concrete surface due to compaction with heavy compactors was a sign of correct compaction. This method insured higher durability and strength of concrete which is proven by some of the structures that are in use to this day.

The reinforcement in reinforced concrete structures did not permit the above mentioned method of compaction. In order to fill all of the space in the formwork a mixture of concrete with a higher dosage of water was needed. Poor casting and more water caused an increase in shrinkage and concrete creep as well as lesser strength and durability.

Freyssinet's idea of vibrating the concrete and the development of a tool that entices vibrations in concrete contributed to better casting of concrete and insured a better quality of the built-in concrete. The use of different types and shapes of vibrators enabled casting of concretes of lesser

*e-mail: Sandra.Juradin@gradst.hr manageability. From the time when L'Hermite tested the effects of vibrations on behaviour of fresh concrete up to now there have been many papers on the subject. However we can still state that the theory and the mechanism of vibrations in concrete, i.e. the correlation between the source of oscillations and the behaviour of fresh concrete, has not been sufficiently examined ${ }^{1-6}$.

The production of high quality and durable concrete is nearly impossible without additives. These additives can be divided into two groups: chemical admixtures and fillers. The most common chemical admixtures are the plasticizer and the superplasticizer that increase workability, i.e. reduce the amount of water needed in the concrete mix. To achieve high flowability as well as stability particles smaller then cement - fine materials can be added to the paste. The best is electrofilter $\mathrm{SiO}_{2}$ (micro silica) that has an average particle size of a few micrometres. Due to its small spherical shaped particles, micro silica insures good cohesion and improved resistance to segregation and is effective in the elimination of bleeding ${ }^{7-10}$. The other often used additive - flying ash is very efficient in increasing cohesion and reducing the sensitivity to changes in the amount of water.

The right ratios of chemical admixtures and fine materials (powder) can produce so called self-compacting concretes (SCC) that can fill any space and any corner in the formwork just through the action of its own weight without the need for vibrations.

The use of SCC is certainly justified and irreplaceable in cases when vibrating is difficult or completely impossible - narrow formwork, lots of reinforcement etc. 
However, one of the questions that engineers encounter is: what if, due to production mistakes, the self-compacting concrete doesn't possess the required properties. The other practical question is: is the usage of SCC justified in conditions of normal casting (pouring), when vibration is possible and is there a need for vibrating SCC when it is used.

The amount of cement and all powder content varies between 450 and $650 \mathrm{~kg} / \mathrm{m}^{3}$. The amount of small particles must prevent the segregation of large aggregate particles and enable their transport to all parts of the formwork ${ }^{11-15}$. The level of compaction of the cast concrete mainly depends on the ability to self-compact. The consequences of insufficient ability to self-compact cannot be fixed once the concrete is in the structure. That's why it is necessary to do everything that is possible to improve the concrete properties before it is cast/placed in the structure. Namely, the likelihood for SCC not to satisfy the requirements of self-compaction in real conditions is always great. Safawi et al. ${ }^{16}$ tested how such SCCs can be improved upon. By measuring the workability of such concretes with the slump-flow method and the $\mathrm{V}$ funnel, they divided the concrete into 4 possible categories and suggested a way of improving such concrete, as shown in Figure 1.

B. Persson ${ }^{17}$, while testing the resistance of SCCs to sulfates, compared the results for the SCCs and those for the corresponding vibrated (normal) concretes. While preparing the specimens he changed the method of mixing of the fresh concrete. He established that the specimens of the SCC kept in the sulfate solution displayed a higher percentage of mass loss than the specimens of the vibrated concrete. The reason was the new method of mixing concrete that was used in the research and a high amount of limestone filler. This proves that the method of preparation and the mixing of the concrete impact its durability.

On the other hand, Laskar ${ }^{18}$ found

It is to be mentioned that it is always difficult to develop a mix design method that can be used universally because same properties of fresh and hardened concrete can be achieved in different ways from same materials.

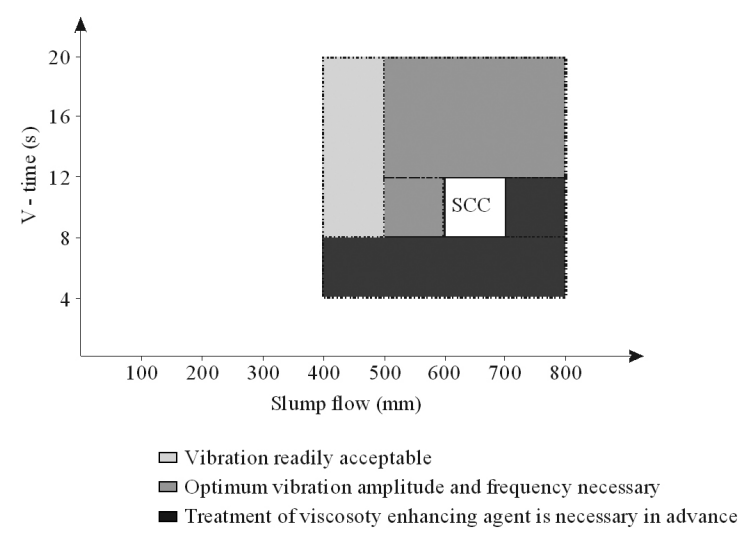

Figure 1. Vibration susceptibility for high fluidity concrete (drawing taken from source ${ }^{16}$ ).
However, regardless of the concrete mixture, what the end user is almost solely interested in is the quality (strength), the appearance of the finished surfaces and the durability of the concrete in its hardened state.

All those factors are interconnected and if the concrete doesn't fill all the space in the formwork it cannot fulfil the required mechanical-physical properties. The areas of poor quality concrete in places where segregation or insufficient compaction occurred are mostly the areas where the process of concrete destruction (failure) starts. The durability of the overall structure is equal to the durability of its weakest place in the structure ${ }^{19}$.

It is to be expected that the use of vibrations during mixing and/or placement of concrete will affect some of the properties that determine the durability of the concrete. Introduction of vibrations in the mixing stage improves the workability and the interface between the cement paste and the aggregate, and vibrations in the casting stage improve the robustness, the compactness of the concrete and formwork placement.

\section{Experimental Testing of the Impact of Vibrations During Mixing}

\subsection{Introduction}

The work examines the impact vibrations during and after mixing have on the appearance of the finished surfaces and the final characteristics of the concrete. The testing was conducted on the specimens of normal and selfcompacting concretes. For the self-compacting concrete the lowest recommended quantity of paste was chosen from the condition to achieve the "borderline" self-compacting concrete. The purpose of the work was to test how such concrete can be improved upon by introducing vibrations during mixing or placement/casting.

Workability was tested in the fresh state for all concretes using the slump method and additionally the slump-flow method for the SCCs. The dynamic module of elasticity and compressive strength were tested in the hardened state.

\subsection{Materials and the contents of the samples}

The testing was conducted on specimens of normal and self-compacting concretes. A series of tests has been performed but only two "typical" recipes have been chosen and shown: one for the normal concrete and the other for the self-compacting concrete of low workability. Labels and sample contents are shown in Table 1. Samples labelled E were prepared and cast in the standard method. The other samples differ by either the mixing or the casting method, as shown in Table 1.

Cement CEM I 42,5 R $\left(3,14 \mathrm{~kg} / \mathrm{dm}^{3}\right)$ and liquid PCE (poly-carboxylic-ether) superplasticizer $\left(1,06 \mathrm{~kg} / \mathrm{dm}^{3}\right)$ were used for both sets of sample series. SCCs were made with silica fume additive, with specific surface area according to Blaine greater than $15000 \mathrm{~cm}^{2} / \mathrm{g}$, and the specific weight is $2,23 \mathrm{~kg} / \mathrm{dm}^{3}$.

The same crashed aggregate was used in the mixtures, except that for normal concrete $\mathrm{D}=31,5 \mathrm{~mm}$ (all 4 aggregate fractions) and for self-compacting concrete $\mathrm{D}=16 \mathrm{~mm}$ 
(first 3 fractions). The chosen maximum aggregate grain sizes are typical for these two types of concrete and have no impact on the final test results because the normal and the self-compacting concretes as such are not compared. The composition and grain size distribution of the crushed limestone is shown in Figure 2. The Figure 2 also shows the chosen granulometric curves of the aggregate used for the normal and the self-compacting concrete samples.

For normal concrete it is a parabolic type curve:

$p=100\left(\frac{d}{D}\right)^{n}$

where exponent $n=0,6$. As it has been previously established $^{19}$, when exponent $\mathrm{n}>1 / 2$, the curve in the diagram is located under the Fuller curve, i.e. the aggregate contains more large grains, the maximum volume concentration of the aggregate is increased but so is the susceptibility for segregation. This type of concrete has good characteristics in its hardened state if it is properly cast, i.e. if the segregation is avoided. That is why this mixture is suitable to clearly show the impact that the introduction of vibrations has during the mixing stage.

In accordance with Table 1 and Figure 2 the contents of the self-compacting concrete can be shown and compared with the evaluation criteria according to EFNARC ${ }^{11}$, Table 2 .

According to Erdem et al. ${ }^{20}$, the total powder content includes the aggregate particles smaller than $0,25 \mathrm{~mm}$. If those particles are excluded, i.e. only the cement and silica fume contents summed up, the total powder content falls again within the recommended values. Table 2 shows that all of the design mixture values fall within the recommended values.

\subsection{The process of sample making and testing}

The usual method of mixing concrete involves: briefly mixing the dry components, followed by mixing with added water for 0,5 minutes, followed by adding the superplasticizer and mixing for further 2,5 minutes.

The preparation of samples that were vibrated during the mixing stage involved: firstly mixing the dry components

Table 1. Descriptions, labels and contents of the test samples.

\begin{tabular}{|c|c|c|c|c|c|}
\hline \multirow{4}{*}{$\begin{array}{l}\text { Concrete } \\
\text { compounds }\end{array}$} & \multicolumn{2}{|c|}{ Normal concrete NC } & \multicolumn{3}{|c|}{ Self-compacting concrete SCC } \\
\hline & ENC & VNC & ESCC & MSCC & VSCC \\
\hline & $\begin{array}{l}\text { standard mixing } \\
\text { and placement for } \\
\text { normal concretes }\end{array}$ & $\begin{array}{l}\text { mixture was } \\
\text { vibrated during } \\
\text { mixing and briefly } \\
\text { during casting }\end{array}$ & $\begin{array}{l}\text { standard mixing } \\
\text { and placement for } \\
\text { SCC concretes (no } \\
\text { vibrations) }\end{array}$ & $\begin{array}{l}\text { mixture was } \\
\text { vibrated during } \\
\text { mixing }\end{array}$ & $\begin{array}{c}\text { mixture was } \\
\text { vibrated during } \\
\text { placement }\end{array}$ \\
\hline & \multicolumn{5}{|c|}{ Mass (kg) for $1 \mathrm{~m}^{3}$ of concrete } \\
\hline Cement & \multicolumn{2}{|c|}{350,00} & \multicolumn{3}{|c|}{400,00} \\
\hline Water & \multicolumn{2}{|c|}{154,00} & \multicolumn{3}{|c|}{200,00} \\
\hline Superplasticizer & \multicolumn{2}{|c|}{3,50} & \multicolumn{3}{|c|}{5,85} \\
\hline Aggregate & \multicolumn{2}{|c|}{1930,10} & \multicolumn{3}{|c|}{1690,20} \\
\hline $0-4 \mathrm{~mm}$ & \multicolumn{2}{|c|}{559,70} & \multicolumn{3}{|c|}{845,10} \\
\hline $4-8 \mathrm{~mm}$ & \multicolumn{2}{|c|}{96,50} & \multicolumn{3}{|c|}{422,50} \\
\hline $8-16 \mathrm{~mm}$ & \multicolumn{2}{|c|}{559,70} & \multicolumn{3}{|c|}{422,50} \\
\hline $16-31.5 \mathrm{~mm}$ & \multicolumn{2}{|c|}{714,10} & \multicolumn{3}{|c|}{-} \\
\hline Silica fume & \multicolumn{2}{|c|}{-} & \multicolumn{3}{|c|}{50,00} \\
\hline Total & \multicolumn{2}{|c|}{2437,60} & \multicolumn{3}{|c|}{2346,00} \\
\hline
\end{tabular}

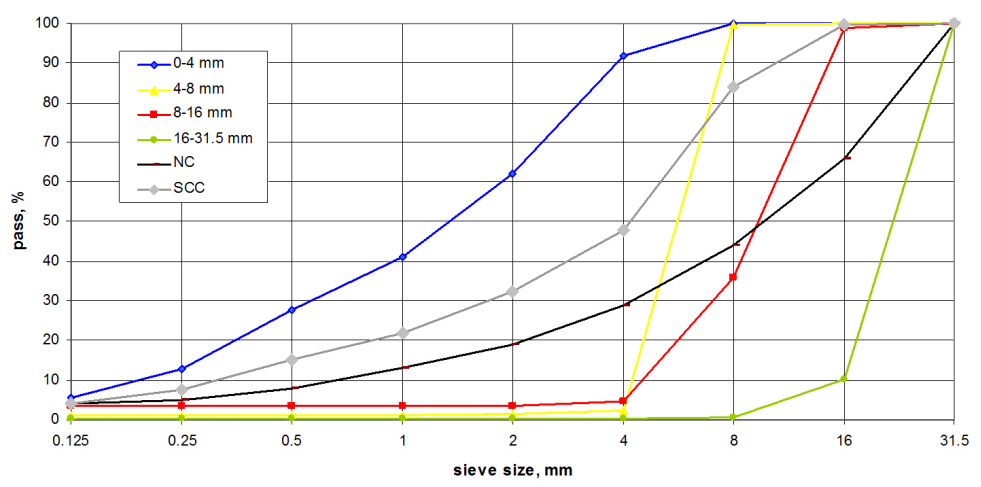

Figure 2. Composition and grain size distribution (Granulometric curve) of the crushed limestone aggregate. 
and then adding water, after 1,5 minutes of mixing the mixer is stopped, the safety lid opened and the mixture vibrated with the pervibrator (Figure 3 ). The duration of vibrating was visually determined by the behaviour of the mixture in the mixer drum. The mixing would then continue for further 1,5 minutes. The vibrator used was the immerseable pervibrator $26 \mathrm{~mm}$ in diameter with the frequency of 18000 turns $/ \mathrm{min}$.

After mixing, slump tests were performed on the normal fresh concrete and slump and slump-flow tests were performed on the fresh self-compacted concrete.

The samples were then cast into cube shaped molds $15 \times 15 \times 15 \mathrm{~cm}$. ENC, VNC and VSCC were vibrated during casting, and ESCC and MSCC were not. VNC was vibrated in the mixing stage as well, so it required less vibration time during casting.

Molded specimens were kept for a day in a room with relative humidity greater than $90 \%$ and temperature $20 \pm 2{ }^{\circ} \mathrm{C}$ after which the specimens were demolded and placed in water till testing day, i.e. 28 days.

Immediately before testing the samples were taken out of the water and wiped dry.

Firstly the mass and all the dimensions of all the test samples were measured, followed by determining the dynamic module of elasticity with the ultrasonic method and testing the compressive strength.

\subsection{Results of the fresh concrete tests}

Results of the slump tests are in Figures 4 and 5.

The results presented in Figure 4, show that the slump of the normal concrete, with the standard mixing and placement

Table 2. Comparison of the design mixture and the suggested typical range from EFNARC ${ }^{11}$.

\begin{tabular}{lcc}
\hline \multicolumn{1}{c}{ Constituent } & SCC & Typical range \\
\hline vol of coarse aggregate $/ \mathrm{m}^{3}(\%)$ & 32,2 & $27-36$ \\
mass sand vs total aggregate $(\%)$ & 50,0 & $48-55$ \\
paste $(\%)(\mathrm{vol})$ & 30,8 & $30-38$ \\
powder $\left(\mathrm{kg} / \mathrm{m}^{3}\right)$ (mass) & 582,9 & $380-600$ \\
water $\left(\mathrm{kg} / \mathrm{m}^{3}\right)$ & 200,0 & $150-210$ \\
water/powder ratio by vol & 1,01 & $0,85-1,1$ \\
water/powder ratio by mass & 0,34 & $0,28-0,37$ \\
\hline
\end{tabular}

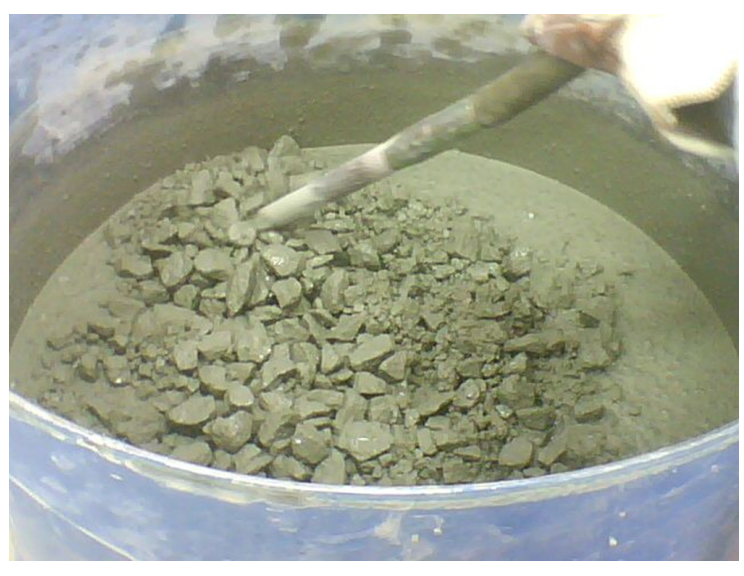

Figure 3. Vibrating during the mixing stage (in the mixer). method (ENC), is slightly lesser than that of the sample with the same content that was vibrated during mixing (VNC). Vibrating during mixing improved the workability of the concrete.

The results show that ESCC and VSCC have almost the same value for the slump while the slump-flow differs slightly, Figure 5. These values were expected considering that by this stage of testing the preparation of ESCC and VSCC is identical. Greater values of slump and slumpflow can be found in the results for the self-compacting concrete that was vibrated during mixing (MSCC) so it can be concluded that vibrating during mixing improved the workability of the self-compacting concrete as well.

Even though the V-funnel test was not performed on the self-compacting concretes (ESCC, MSCC and VSCC), it is evident from the size of the slump that this concrete would have a long flow time (longer than $8 \mathrm{~s}$ ), so, according to Figure $1^{16}$, it belongs in the category of concretes for which vibrating is recommended, which was the intention. This is also confirmed by the results of the L-box and J-ring tests where blockage occurred, Figure 6.

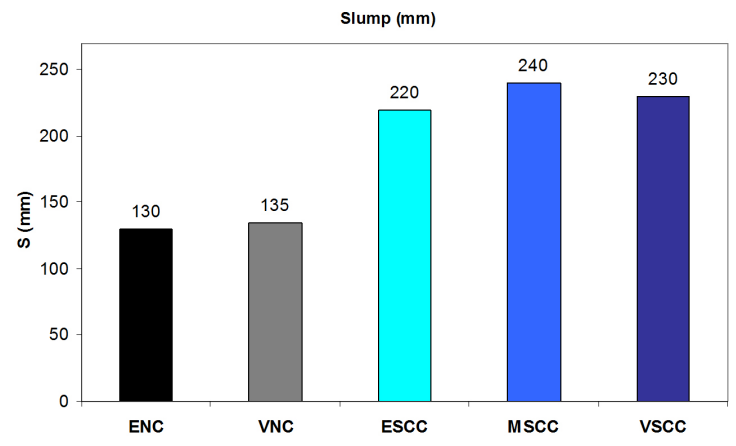

Figure 4. Results of the slump test of all the test concretes.

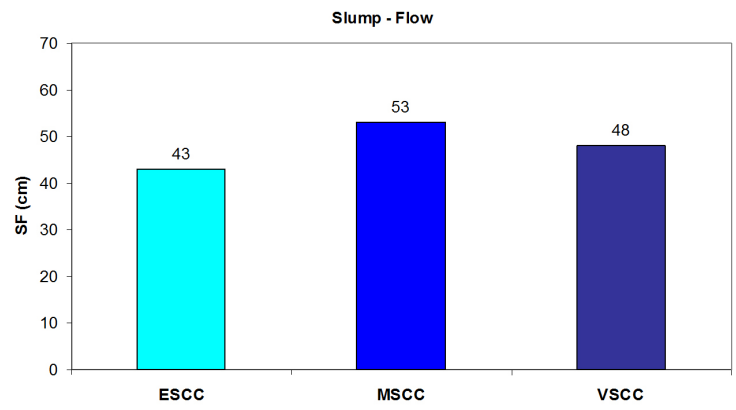

Figure 5. Results of the slump flow test of the SCCs.

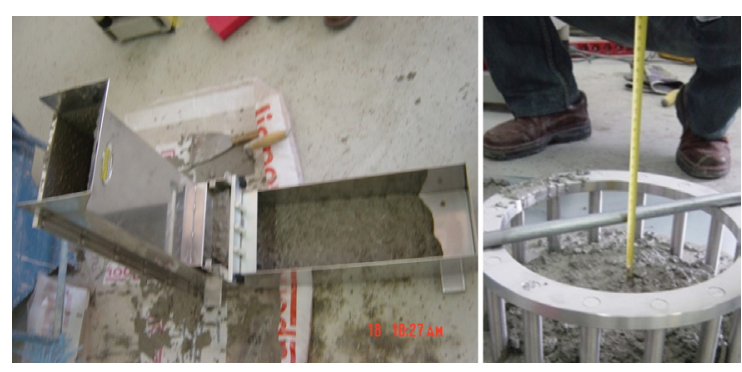

Figure 6. L-box and J-ring testing. 


\section{Results and Discussions}

\subsection{Results of the dynamic modulus of elasticity test}

The dynamic modulus of elasticity is determined by measuring the velocity by which the ultrasound wave passes through the test sample:

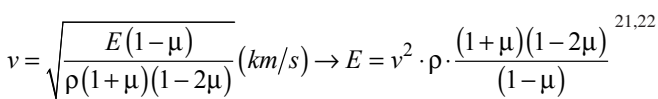

where:

- E - the dynamic modulus of elasticity

- $\rho$-density

- $\mu$-Poisson's coefficient

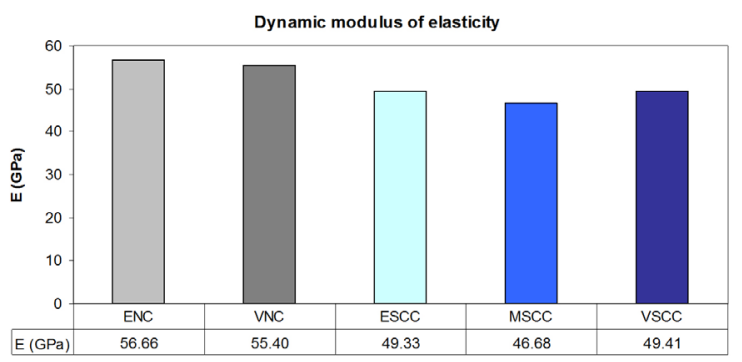

Figure 7. The dynamic modules of elasticity for the tested concretes.

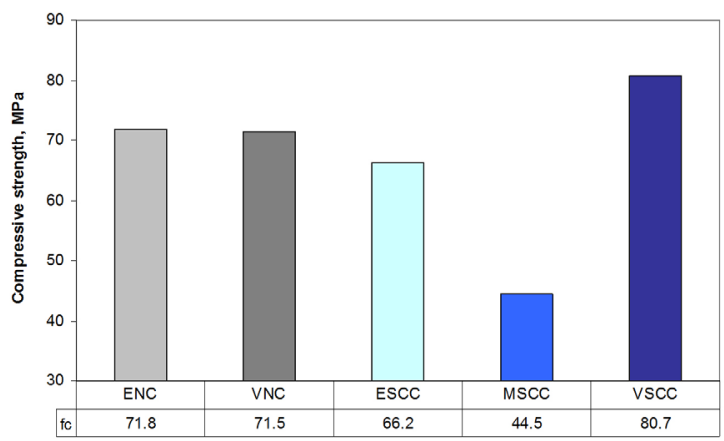

Figure 8. Average compressive strength of normal concrete samples.

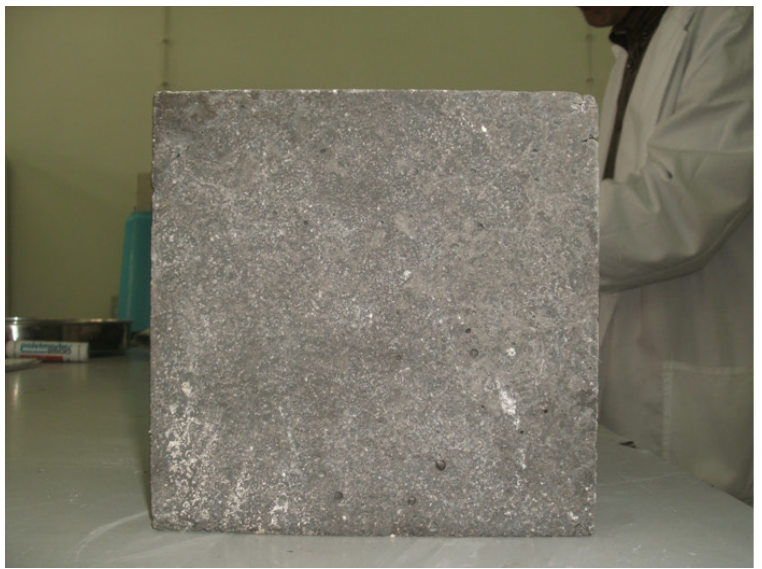

The density $(\rho)$ of the test samples is within the range of $2249,21-2473,23 \mathrm{~kg} / \mathrm{m}^{3}$, Poison's coefficient $(\mu)$ is 0,2 according to $^{23}$. The measured ultrasound speeds are within the range of $4756,9-5084,7 \mathrm{~m} / \mathrm{s}$.

The measured values are shown in Figure 7.

The results of the dynamic modulus of elasticity tests for the normal concretes show that the ENC specimens have somewhat greater values of the dynamic modulus of elasticity than the sample of the same contents that was vibrated in the mixing stage, but the difference is minimal on the scale of $1 \mathrm{GPa}$.

The results of the dynamic modulus of elasticity test for the self-compacting concretes show that the specimens of the concrete that was vibrated during the casting stage (VSCC) have the greatest average value of the dynamic modulus of elasticity, but only slightly greater than the ESCC specimen. The specimens of the self-compacting concrete that was vibrated in the mixing stage (MSCC) have the lowest average value of the dynamic modulus of elasticity.

Since all the differences are small, the general conclusion is that the method of mixing and vibrating doesn't have a great influence on the dynamic modulus of elasticity.

\subsection{Results of the compressive test}

Compressive strength was determined in accordance with HRN EN 12390-3. The achieved results of the compressive strength test are shown in Figure 8.

Results of the compressive strength test at 28 days show that normal concrete samples (ENC) have almost identical compressive strength as VNC. It can be concluded that, when the concrete mix is stable, the usual time and method of mixing are completely satisfactory. In other words, the introduction of vibrations in the mixing stage does not contribute to the quality of concrete and that in this case mixing is superfluous.

The samples of the self-compacting concrete that was vibrated in the casting stage (VSCC) have, by far, the highest strength. The samples of the self-compacting concrete that was vibrated during the mixing stage (MSCC) have the lowest strength. The differences between the values of the compressive strength are extremely high even though the concrete mix content is the same.

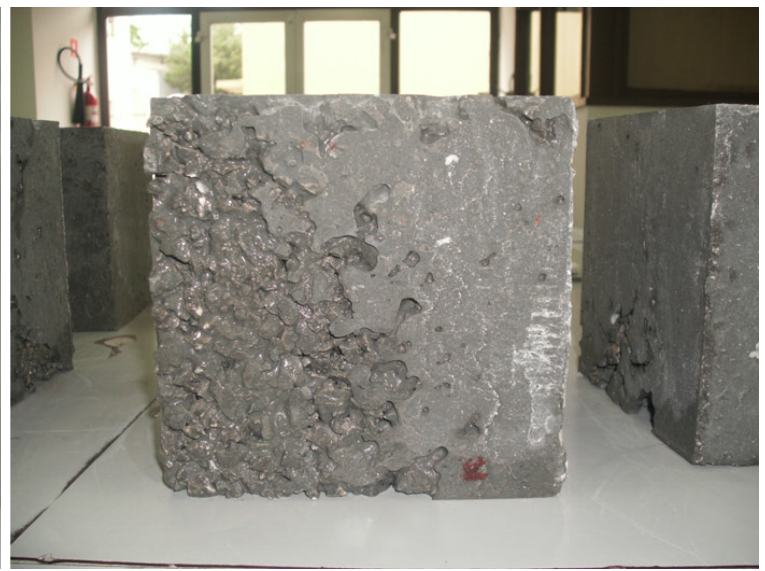

Figure 9. The appearance of the surface of ESCC samples - two samples (good - left, bad - right). 

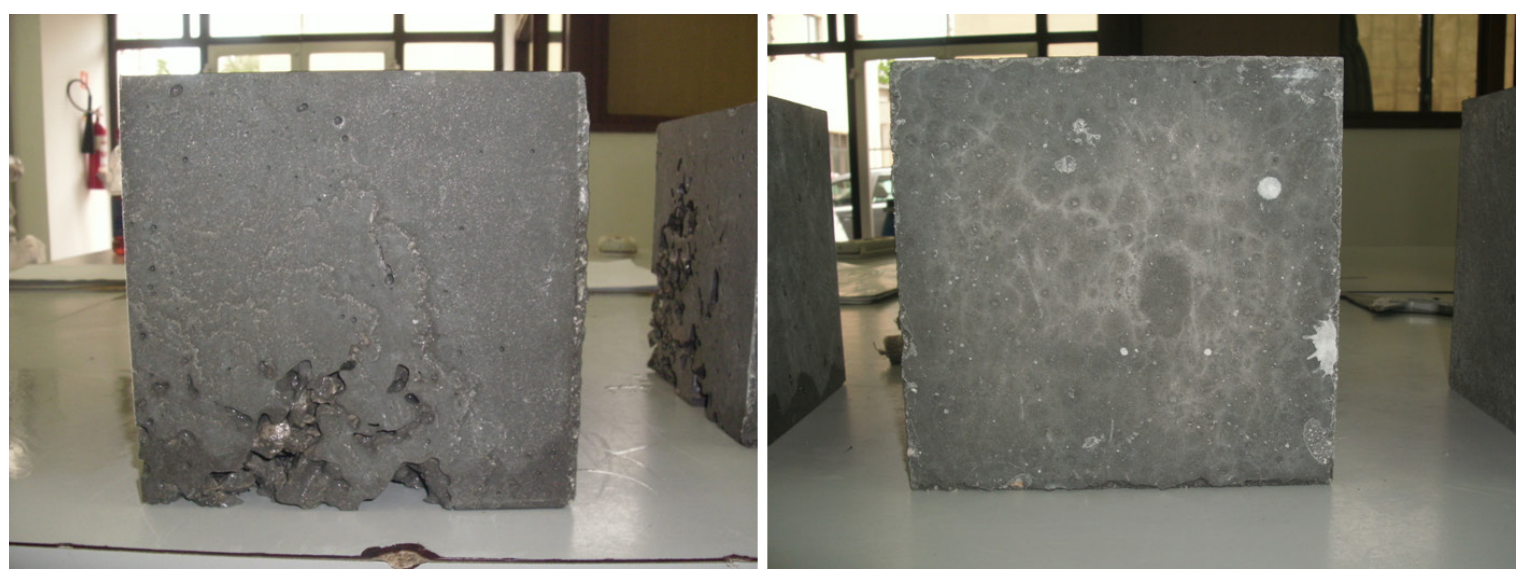

Figure 10. The appearance of the surface of MSCC (left) and VSCC (right).

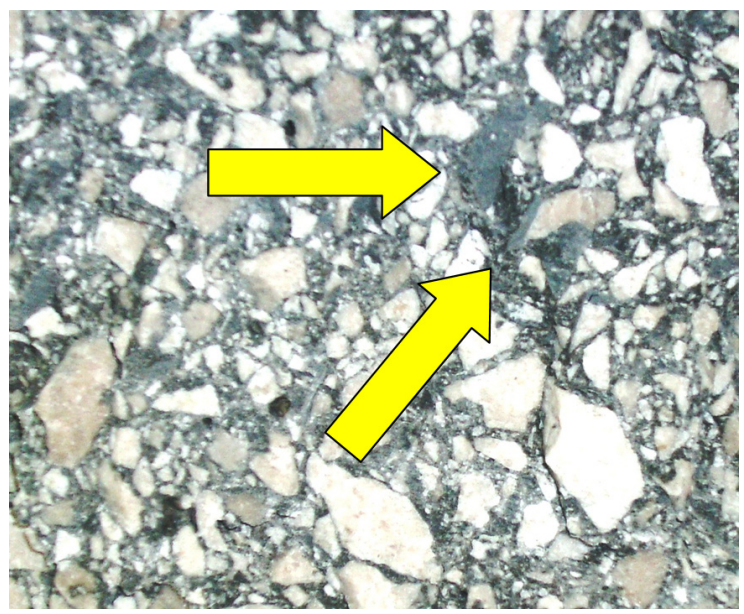

Figure 11. Surface of the VSCC specimen after failure.

\subsection{Hardened self-compacting concrete}

The appearance of the surface of the hardened SCCs is shown in Figures 9 and 10.

Figure 9 shows two samples of the same concrete mix (ESCC). It is clear from the photos that the concrete is not fully self-compacting and needs assistance during placement/casting either by poking with a stick, by shaking the mould or with vibrations. Similar appearance is evident in MSCC (Figure 10). Only the VSCC had all the satisfactory surfaces. It is evident from Figure 10 that the introduction of vibrations during the mixing stage cannot replace vibrations during the placement/casting, at least not for the tested concrete types.

After the compressive strength tests of the selfcompacting concrete samples, areas of nonhydrated cement and silica fume particles were noticed in the structures of the ESCC and VSCC samples, Figures 11 and 12.

This wasn't that noticeable in the MSCC specimens that were vibrated during the mixing. The concrete with a lower degree of cement hydration generally has lower gel porosity, which explains the well-known fact that this type of concrete has greater compressive strength and betters

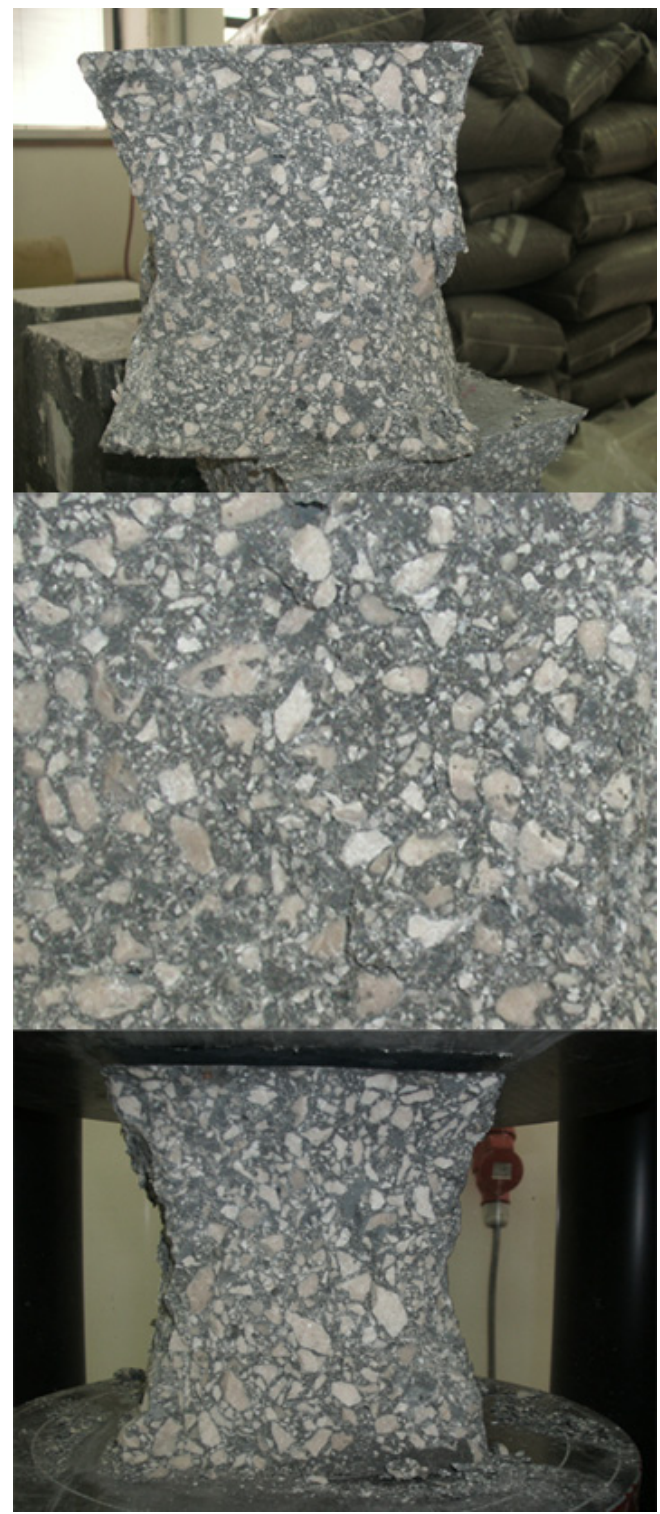

Figure 12. ESCC, MSCC and VSCC specimens after compressive strength tests. 
other properties although it has a lower degree of hydration ${ }^{19}$. According to Figure 8, ESCC and VSCC have significantly greater compressive strength than the MSCC.

\section{Conclusions}

Lack of qualified workers led to the development of the self-compacting concrete that has the ability to flow, selfcast and compact under its own weight without vibrating. For that to be possible, the self-compacting concrete must contain a greater amount of paste as a transport means and a lesser amount of aggregate to prevent flow blockages. The use of this concrete enables high durability of concrete structures and eliminates the noise of vibrating and shortens the construction time.

Designing the SCC mixture is a complex task. Obeying the recommended contents and the ratio of the components of the self-compacting concrete is not a guaranty that the end result will be a concrete that has the ability to selfcompact. Mistakes during casting produce areas in concrete of lesser quality that have a great impact on the durability of the overall structure because those are the areas were the reinforcement corrosion process begins.

The work examines the impact vibrations in the mixing stage and vibrations in the casting stage have

\section{References}

1. Neville AM. Properties of Concrete. Pearson Eduaction Limited; 2000.

2. Wünsch O. Oscillating sedimentation of spheres in viscoplastic fluids. Rheologica Acta. 1994; 33:292-302. http://dx.doi. org/10.1007/BF00366955

3. Teranishi K, Tanigawa Y, Mori H and Tarada K. Study on sinking behavior of coarse aggregate in fresh concrete subjected to vibration. Transactions of the Japan Concrete Institute. 1995; 17:1-8.

4. Frantzis P and Baggott R. Effect of Vibration on the Rheological Characteristics of Magnesia Phosphate and Ordinary Portland Cement Slurries. Cement and Concrete Research. 1996; 26(3):387-397. http://dx.doi.org/10.1016/ S0008-8846(96)85026-5

5. American Concrete Institute - ACI. ACI Committee 309: Behaviour of Fresh Concrete During Vibration. ACI Journal. 1981; 78(1):36-53.

6. American Concrete Institute - ACI. ACI Committee 309: Behaviour of Fresh Concrete During Vibration, Reapproved. ACI; 1998.

7. Nazari A and Riahi Sh. The effects of $\mathrm{SiO}_{2}$ nanoparcticles on physical and mechanical properties on high strength compacting concrete. Composites Part B: Engineering. 2011; 42(3):570578. http://dx.doi.org/10.1016/j.compositesb.2010.09.025

8. Nazari A and Riahi Sh. The role of $\mathrm{SiO}_{2}$ nanoparcticles and ground granulated blast furnace slag admixtures on physical, thermal and mechanical properties on self compacting concrete. Materials Science and Engineering: A. 2011; 528(4-5):21492157. http://dx.doi.org/10.1016/j.msea.2010.11.064

9. Nazari A and Riahi Sh. Microstructural, thermal, physical and mechanical behavior of the self compacting concrete containing $\mathrm{SiO}_{2}$ nanoparticles. Materials Science and Engineering: A. 2010; 527:7663-7672. http://dx.doi.org/10.1016/j.msea.2010.08.095 on the compressive strength of concrete after 28 days using samples of normal concrete and "borderline" selfcompacting concrete - produced in real conditions (i.e. construction sites).

Results of the testing show that:

- The introduction of vibrations in the mixing stage improves the formability of fresh concrete;

- Vibrations in the mixing or the casting stage had no significant impact on the dynamic module of elasticity of the normal or the self-compacting concrete;

- Vibrations in the mixing stage had no impact on the strength of the normal concrete, but it significantly reduced the strength of the self-compacting concrete;

- The highest strength was achieved by the samples of the concrete that was vibrated during the casting stage, which is a consequence of the formwork being thoroughly filled. Even though those were samples of the self-compacting concrete (SF smaller than $500 \mathrm{~mm}$ ), additional vibrations improved the compactness of the concrete which resulted in the increased compressive strength and improved appearance of the concrete surface, and, with it, its durability.

10. Vaičiukyniene D, Vaitkevičius V, Kantautas A and Sasnauskas V. Utilization of by-product waste silica in concrete based materials. Materials Research. 2012; 15(4):561-567.

11. European Guidelines for Self-Compacting Concrete Specification, Production and Use. BIBM, CEMBUREAU, EFCA; EFNARC, ERMCO; May 2005.

12. Spiratos N, Page M, Mailvaganam N, Malhotra VM and Jolicoeur C. Superplasticizers for Concrete, Fundamentals, Technology and Practice. Ottawa: Supplementary Cementing Materials for Sustainable Development Inc; 2003.

13. Okamura $\mathrm{H}$ and Ouchi M. Self-Compacting Concrete. Journal of Advanced Concrete Technology. 2003; 1(1):5-15. http:// dx.doi.org/10.3151/jact.1.5

14. Khrapko M. Self Compacting Concrete-a Solution for Technology Hungry Concrete Construction. In: Proceedings of Civil Engineering Testing Conference; 2008; New Zealand. New Zealand; 2008

15. Collepardi M. Self-compacting concrete: What is new?. In: Proceedings of the Seventh CANMET/ACI International Conference on Superplasticizers and Other Chemical Admixtures in Concrete; 2003; Berlin. Berlin; 2003. p. 1-16.

16. Safawi MI, Iwaki I and Miura TA. Study on the applicability of vibration in fresh high fluidity concrete. Cement and Concrete Research. 2005; 35(9):1834-1845. http://dx.doi.org/10.1016/j. cemconres.2004.10.031

17. Persson B. Sulphate resistance of self-compacting concrete. Cement and Concrete Research. 2003; 33(12):1933-1938. http://dx.doi.org/10.1016/S0008-8846(03)00184-4

18. Laskar AI. Mix design of high-performance concrete. Materials Research. 2011; 14(4):429-433. http://dx.doi.org/10.1590/ S1516-14392011005000088

19. Krstulović P. Svojstva i Tehnologija Betona (The Properties and Technology of Concrete). IGH Split; 2000. [in Croatian].

20. Erdem TK, Khayat KH and Yahia A. Correlating Rheology of Self-Consolidating Concrete to Corresponding ConcreteEquivalent Mortar. ACI Materials Journal. 2009; 106(2):154-160. 
21. Zheng LE. Experimental investigation on dynamic properties of rubberized concrete. Construction and Building Materials. 2008; 22:939-47. http://dx.doi.org/10.1016/j. conbuildmat.2007.03.005

22. Rahman MM, Usman M and Al-Ghalib AA. Fundamental properties of rubber modified self-compacting concrete (RMSCC).
Journal of Construction and Building Materials. 2012; 36:630637. http://dx.doi.org/10.1016/j.conbuildmat.2012.04.116

23. Kumar M, Asce AM, Ma Z and Matovu M. Mechanical Properties of High-Strength Concret. Available from: $<$ http://www.acsu.buffalo.edu/ mkumar2/Wikiquake/Docs/ ReportHSC.pdf>. 